\title{
Analysis of ways to combat the sticking of rocks on the working equipment of mining machines
}

\author{
Mariya Mamaeva $^{1 *}$, Ilya Muagkih ${ }^{1}$, and Olga Semenova ${ }^{1}$ \\ ${ }^{1}$ T.F. Gorbachev Kuzbass State Technical University, Branch of Prokopievsk, 19a \\ Nogradskaya str., Prokopievsk, 653039, Russian Federation
}

\begin{abstract}
The article discusses ways to reduce energy consumption in the open-pit mining of minerals in the conditions of Kuzbass by reducing the sticking to the working automobile equipment and excavator complexes. When excavating and transporting cohesive rocks, due to a sharp change in climatic conditions, adhesioncryogenic processes occur (sticking, freezing on excavator buckets, dumpcars, conveyor belts, dump truck bodies, etc.). This significantly reduces the efficiency of excavating and transport complexes. In this paper, we consider the adhesion-cryogenic processes affecting the rock, methods of anti-sticking for the selection of optimal solutions.
\end{abstract}

\section{Introduction}

When excavating and transporting cohesive rocks, due to a sharp change in climatic conditions, adhesion-cryogenic processes occur (sticking, freezing on excavator buckets, dumpcars, conveyor belts, dump truck bodies, etc.), which significantly reduces the efficiency of excavating and transport complexes.

\section{Formulation of the problem}

Complex geological and climatic conditions are accompanied by changes in the properties and conditions of cohesive rocks during mining. In the operation of mining and overburden complexes these changes are the reasons for the decrease in performance indicators.

The geographical location of the territory of Kuzbass determines its climatic features. According to the normative documentation of SP 131.13330.2018 "SNiP 23-01-99* [1] Construction Climatology", Kuzbass belongs to the climatic region I, subdistrict IB, in which the average monthly temperatures in winter range from -14 to -28 , and in summer from +12 to $+21{ }^{\circ} \mathrm{C}[2]$. Precipitation in the territory under consideration, depending on the season, falls in the form of snow, rain or have a mixed character.

${ }^{*}$ Corresponding author: mameva-mariya2012@yandex.ru 
Data on the average monthly humidity of the air are given for the months of the AMSG Novokuznetsk in Table 1[2].

Table 1. Data on the average monthly air humidity are given by the months of the AMSG Novokuznetsk

\begin{tabular}{|c|c|c|c|c|c|c|c|c|c|c|c|c|c|}
\hline Months & I & II & III & IV & V & VI & VII & VIII & IX & X & XI & XII & year \\
\hline Humidity, \% & 80 & 78 & 74 & 66 & 60 & 67 & 72 & 75 & 75 & 77 & 81 & 81 & 74 \\
\hline
\end{tabular}

The average annual relative humidity is $74 \%$. The average monthly relative humidity of the air at $3 \mathrm{pm}$ in the coldest month-74\%. The average monthly relative humidity at $3 \mathrm{pm}$ in the warmest month is $52 \%$.

The change in the average relative humidity of the air during the operation of mining equipment is shown in Fig. 1.

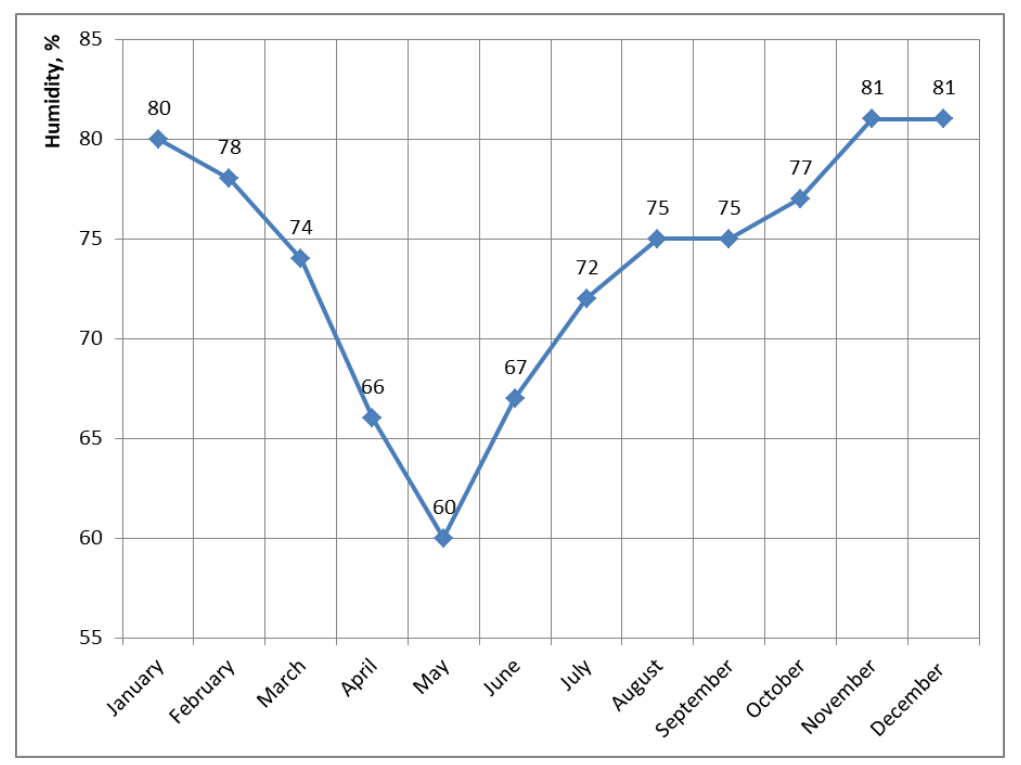

Fig. 1. Changes in the average relative humidity of the air during the operation of mining equipment.

The environmental situation of any mining enterprise is largely related, and directly depends on the wind rose, the nature of moving air flows in accordance with weather and climatic conditions. It is necessary to take into account the terrain and elevation markers of the area. In order to solve this problem, firstly it is necessary to consider how the adhesion-cryogenic processes affect the rock. The mechanical properties of rocks depend on their structure, which in turn characterized by the structure and texture of rocks. The main petrographic classifications [3] served as the basis for constructing the most general geomechanical classification of rocks (Fig. 2). 


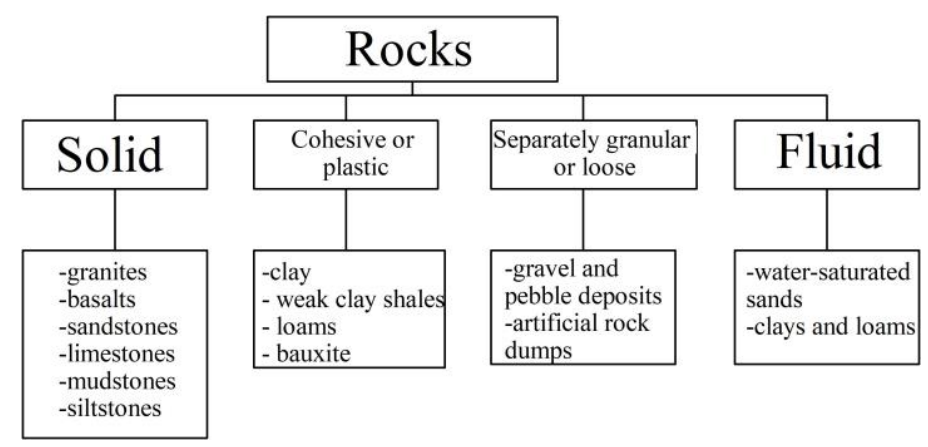

Fig. 2. General geomechanical classification of rocks.

In the Kuznetsk coal basin soils consist of a mixture of sandy, powdery and clay particles. They are most often found and the have the greatest influence on the mechanical properties of the soils. Therefore, classified soils depend on the number of clay particles that are in it, and the number of plasticity determined by the presence of these particles $\mathrm{Jp}[4]$.

You need to consider options for cleaning and preventive treatment of work surface in order to calculate the optimal method:

1. Manual cleaning of the bucket (with the help of improvised tools)

2. Heating the bucket

3. Liquid preventive coatings

4. Modernization of buckets (making changes to the design of working equipment)

Manual cleaning can include cleaning with the help of improvised tools, such as a sledgehammer, scrap, log, etc. The advantages of this method include efficiency and timeliness. The disadvantages are the severity and duration of the process, the inability to use with large amounts of freezing (sticking) [5].

When warming up the bucket, the advantages will be the ease of lagging the rock from the surface of the bucket, while maintaining the optimal temperature of the metal. If you do not maintain the frequency of heating, there may be mechanical damage to the bucket (cracks, etc.). Also, this method is environmentally dangerous, due to the fact that tires are usually used for heating, smoke emission is harmful to the environment [6].

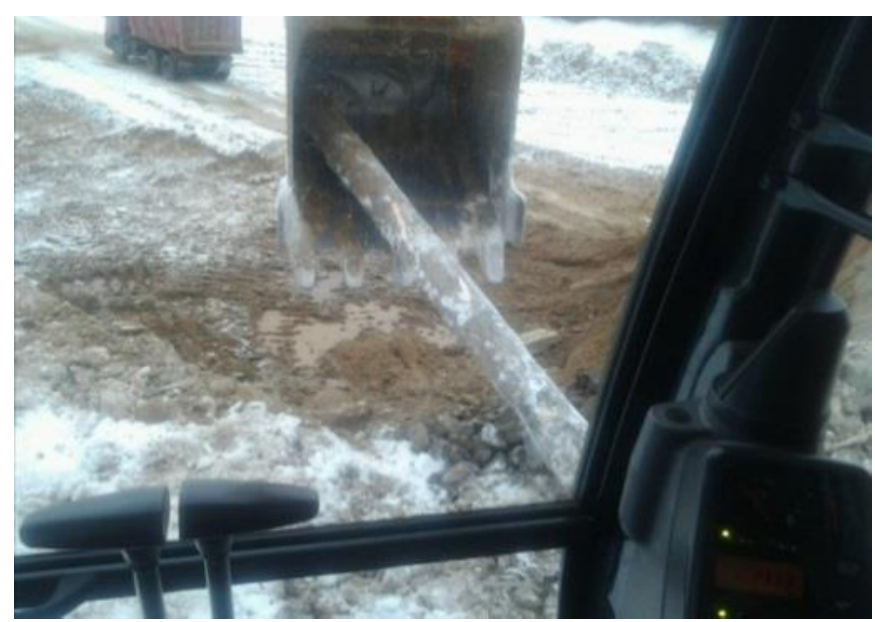

Fig. 3. Manual cleaning of the bucket with the help of improvised devices. 
When treating bucket surfaces with various solutions that prevent rock sticking and freezing, the main drawback is the short-term preventive effect of the recommended liquids and solutions [7].

During the patent search several methods and design solutions were identified, aimed at reducing the adhesion of the soil and reducing the labor intensity of its cleaning. Let's consider some of them:

1. Author's certificate of the USSR No. 658230 of 1977 "Method of cleaning the excavator bucket" (Fig. 4) the authors of which are Filatov V. F., Makarov V. N.

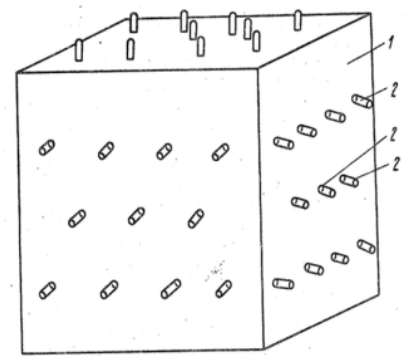

Fig. 4. Method of cleaning the excavator bucket.

The disadvantage of this method is that there is also significant wear of the metal surface of the bucket during mechanical cleaning in addition to erasing the stuck soil.

2. Copyright certificate of the USSR No. 872658 registered in 1979, authors Pavlov V. P., Minin V. V., Nazarov G. G. "Excavator bucket cleaning unit" This design is complex in its execution (in working conditions it is not suitable for field repairs), and the unit has a sufficiently large mass (the bucket weight increases).

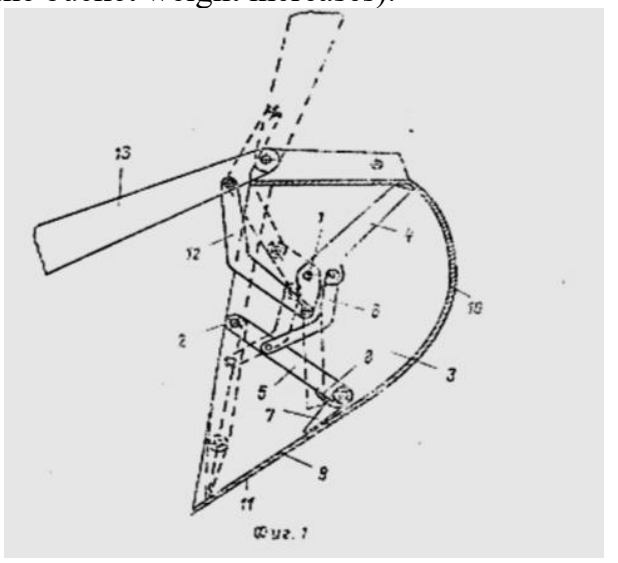

Fig. 5. Excavator bucket cleaning unit.

3. Copyright certificate of the USSR No. 1168674 registered in 1984, authors Butkevich G. R., Shpak L. D., Karpova T. N., Kuzmin I. I., Garbuzov M. S. "Device for cleaning the excavator bucket" The disadvantages of this design are the complexity of the design and the stationary placement of the invention. 


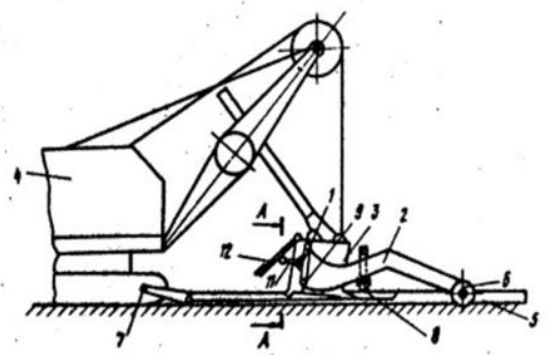

Fig. 6. Device for cleaning the bucket of the excavator.

4. The following technical solution is developed basically on the actual operating conditions when working with highly adhesive rocks (clay). It does not have an author's certificate. The chains are welded instead of the bottom wall of the bucket and have freedom at the extreme points of movement. The disadvantages of this design are the inability to work with loose and fine-grained soils.

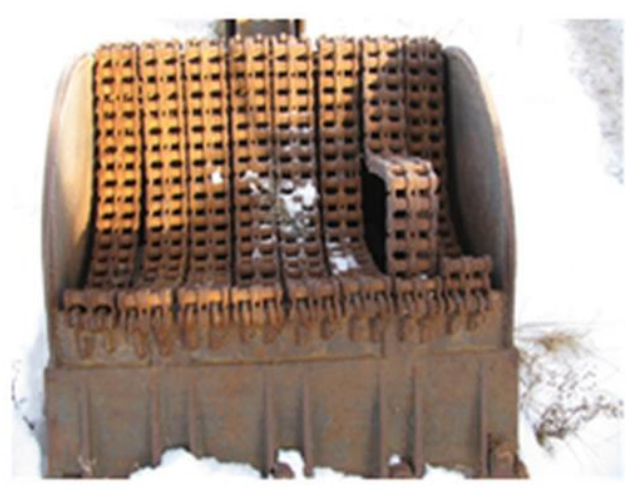

Fig. 7. The bottom of the excavator is made in the form of chains.

\section{Research result}

To sum up we can say that the above methods and means of combating adhesion-cryogenic processes, despite their diversity, are not effective enough in most cases.

To suggest effective ways and means to combat sticking you firstly need to determine what causes this process. In the process of moving waterlogged cohesive rocks that are prone to sticking their adhesive interaction with the working surfaces is carried out through the liquid cuff. The quantitative values of its stickiness and stickiness are determined by the capillary and molecular components.

Thawed overburden rocks in the process of their movement at positive ambient temperatures are characterized by the stickiness criterion determined from the expression [8]:

$$
\mathrm{K}_{\mathrm{N}}=\frac{\mathrm{F}_{\mathrm{aд}}}{\mathrm{F}_{\mathrm{ayr}}}
$$

were $\mathrm{F}_{\text {ад }}$-where is the strength of adhesion, $\mathrm{N} / \mathrm{m}^{2} ; \mathrm{F}_{\text {аут }}$ - the strength of autohesia, $\mathrm{N} / \mathrm{m}^{2}$.

In this case, the adhesion force is determined quantitatively by the amount of adhesion of the rock mass to the working surface. The adhesion force is determined by the strength of the bond between the rock particles. 
When unloading rocks from vehicles, in the case of $F_{-}$ad $<F$ _out, the separation occurs along the contact line of the rock with the working surface of the mining equipment, and if F_ad $>$ F_out, then the break line will pass inside the rock [9-10].

In Kemerovo region soils by the type of internal bonds are classified as cohesive soils, with elastic, reversible mainly water-colloidal bonds. They belong to the group of clay and dusty. The main features of such soils are plasticity and some water-physical properties (soaking, swelling, stickiness, etc.).

The separation forces that occur at the boundary of the "ground - working equipment"section cause the stickiness. The amount of stickiness mainly depends on the granulometric and chemical-mineral composition of the soil, as well as on their humidity. The triangular diagram shows the granulometric composition (Fig. 8).

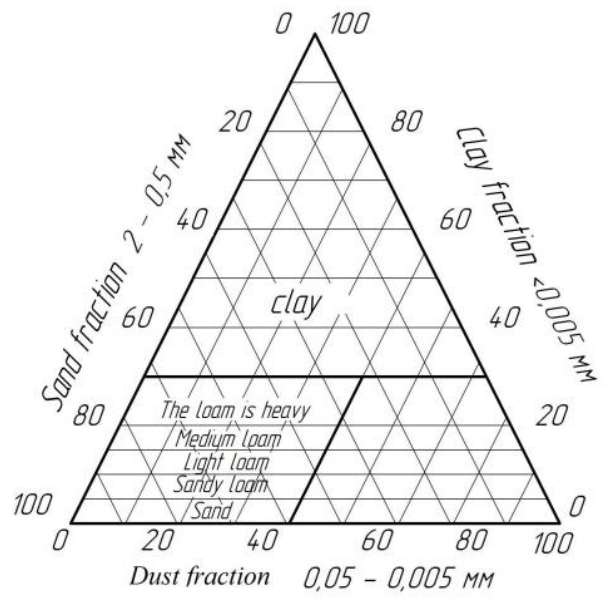

Fig. 8. Triangular diagram of the granulometric composition.

Stickiness is characteristic of clay and partly dusty soils that are in a moistened state. It has a negative impact on the excavation of excavated complexes. Reaches a maximum, in a certain range of humidity causes large deformations of the surface layer of the soil, which causes adhesion to various working surfaces (Fig. 9).

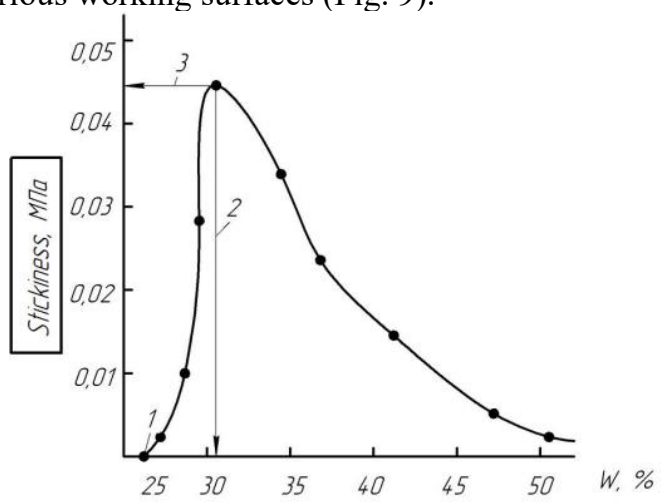

Fig. 9. Graph of the dependence of the stickiness of clay soil on humidity.

In this case, the adhesion force is determined quantitatively by the amount of adhesion of the rock mass to the working surface. The adhesion force is determined by the strength of the bond between the rock particles. Due to the presence of a temperature difference, there will 
be a thermal diffusion of moisture. As a result, there is a change in humidity in the rock surface layer at the place of adhesive contact.

The authors show that rocks have weak adhesion to each other at high humidity [11].

It is also necessary to consider the process of heat transfer at the adhesive contact in order to develop recommendations and methods for the direction of changes in the conditions of adhesion (adhesive interaction) of the transported rock mass with the working surfaces .

In addition to the ambient temperature, atmospheric precipitation plays an important role. When it falls on the working surfaces, moisture is formed, which forms a film that contacts the rock and changes the adhesion of the rock mass.

The analysis of numerous sources revealed a large number of factors that affect the processes of reducing resource costs in the operation of mining machines[12-15].At the same time the sticking to the working equipment is significantly influenced by the factors shown in Fig10.

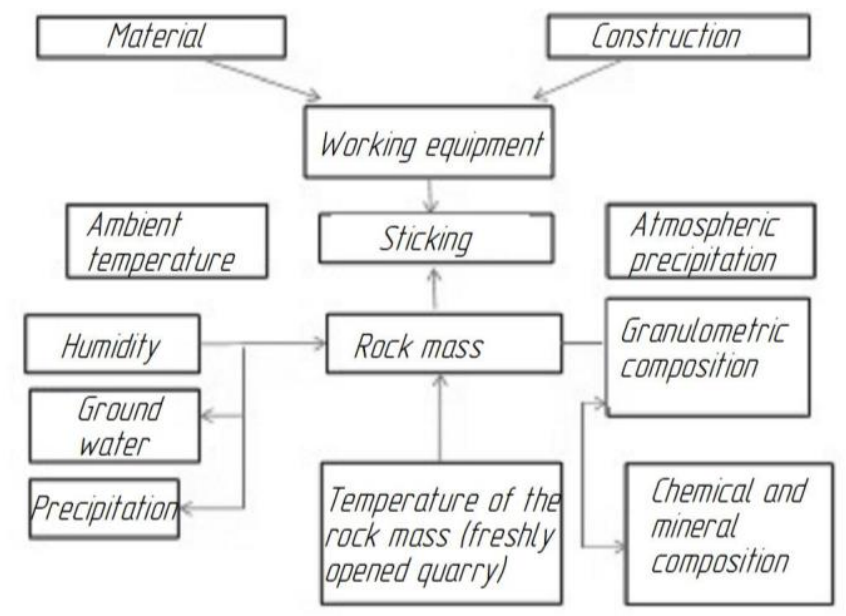

Fig. 10. Factors affecting the process of rock sticking.

When the quarry is deepened, the temperature of the rock mass increases by about 1 degree30 meters. The use of materials for covering working surfaces created on the basis of oil refining (used oils, oils, diesel fuel) is expensive and not environmentally friendly. As an analog, it is proposed to use a moisture-resistant inert dust, which is used in the coal mining and coal processing industry to prevent and extinguish coal dust explosions, as well as in fire-fighting equipment for extinguishing fires.

Inert dust, consisting of non-combustible materials, reduces the ambient temperature during the combustion and explosion of coal dust and methane. It is used to prevent the occurrence of flames in production.

\section{Conclusion}

Thus, the use of inert dust in the processing of metal surfaces of the working equipment of the automobile and excavator complex reduces sticking, increasing the working volume of buckets and bodies. Such inert dust has characteristics of asignificant hygroscopicity, which is resultatively quickly caked. Moisture-resistant inert dust remains loose for a long time and during processing of the working surfaces. It will settle not only on the working surface, but also on the rock mass, balancing the temperature difference and humidity. That mainly causes the rock mass to stick to the surface of the working equipment of excavator-automobile complexes. For spraying, you can use devices for applying powder materials to various 
products, using compressed air and spray nozzles installed on the working surfaces. The design of this equipment is under development.

\section{References}

1. K. Fujita et al., Hitachi Review, 60, 267 (2011)

2. H. Yamamoto et al., Hitachi Review, 58, 251(2009)

3. S. Okabe, Japan Industrial Publishing Co. (2007)

4. W. Bartelmus, Editorial statement, Mechanical Systems and Signal Processing, 38, 1 (2013)

5. W. Bartelmus, Key Engineering Materials. 588, 184 (2014)

6. A. Goodbody, Smooth Operations Mining Magazine July/August, 44 (2013).

7. M. Sawicki, P. Stefaniak, R. Królet al., International Journal of Transport \& Logistics (Belgrade), 10, 263 (2012)

8. P. Stefaniak, A. Wylomanska, J. Obuchowski, R. Zimroz, 12th International Symposium Continuous Surface Mining, Aachen (2014)

9. R. Zimroz, W. Bartelmus, T. Barszcz, Mechanical Systems and Signal Processing, 26, $16(2015)$

10. R. Zimroz, P. Stefaniak, W.Bartelmus, et al., 12th International Symposium Continuous Surface Mining, Aachen (2014)

11. E. Pudov, E Kuzin, A. Efremenkov, et al. IOP Conf. Ser.: Mater. Sci. Eng., 253, 012063 (2020)

12. M. Mamaeva, E. Kuzin E. MATEC Web of Conferences 297, 03006 (2019)

13. B. Gerike, I. Panachev, E. Kuzin, E3S Web of Conferences, 15, 03008 (2017)

14. Lubyanoi, E. Pudov, E. Kuzin, O. Semenova, R. Rybár E3S Web Of Conferences 242 , $03022(2020)$

15. Kuzin,M. Mamaeva, B. Gerike, K. Singh E3S Web Of ConferencesIVth International Innovative Mining Symposium, 209, 03011 (2019) 